\title{
Tipologi Taman-Taman Kota berdasarkan Sense of Place Pengunjung
}

\author{
Jasmine C. U. Bachtiar ${ }^{1}$ dan Hanson E. Kusuma ${ }^{2}$ \\ ${ }^{1}$ Magister Arsitektur, SAPPK, Institut Teknologi Bandung \\ ${ }^{2}$ Kelompok Keahlian Perancangan Arsitektur, SAPPK, Institut Teknologi Bandung \\ jcubachtiar@gmail.com
}

\begin{abstract}
ABSTRAK
Jumlah rasio area hijau kota khususnya taman-taman kota mulai berkurang seiring dengan pemenuhan kebutuhan masyarakat akan fasilitas umum. Taman-taman kota, di lain pihak, memiliki banyak sekali manfaat bagi penduduk sekitar sehingga harus dilestarikan agar tidak terancam hilang. Penelitian ini ditujukan untuk mengetahui bagaimana pengelompokan (tipologi) jenis taman-taman di area kota berdasarkan sikap yang ditunjukkan oleh pengunjung ketika berada di taman (sense of place). Data penelitian dikumpulkan melalui kuesioner daring dan mendapatkan sejumlah 211 responden. Data kemudian diolah secara kualitatif dengan metode open coding, axial coding, dan selective coding. Hasil menunjukkan terdapat dua kelompok taman di area kota yaitu taman restorasi dan taman hutan. Taman restorasi biasanya mewadahi kegiatan restorasi yang dapat dilakukan sehari-hari, sementara taman hutan dapat mewadahi kegiatan restorasi dan hobi yang ingin dilakukan pengunjung. Berdasarkan durasi kunjungannya, tingkat sikap pengunjung terhadap tempat di taman hutan lebih tinggi dibandingkan dengan taman restorasi. Peran arsitek dan perancang kota dibutuhkan untuk mendesain taman-taman kota yang dapat meningkatkan sikap pengunjung terhadap tempat, seperti menyediakan tempat yang mewadahi atraksi, kegiatan olahraga, jalan kaki, fotografi, relaksasi, dan menikmati suasana.
\end{abstract}

Kata kunci: Durasi kunjungan, sikap terhadap tempat (sense of place), taman kota, tipologi taman

\begin{abstract}
The provision of urban green areas, especially urban parks, has been decreasing as higher demand for public facilities in the city. Urban parks, however, provide many benefits for surrounding residents that require effort to sustain them. The current study wants to identify how grouping (typology) of urban parks was based on visitor's attitudes toward urban parks (sense of place). The data were collected online from the questionnaire, and the data of 211 respondents were collected. The data were then processed quantitatively by open coding, axial coding, and selective coding analyses. The result shows that there were two groups of urban parks based on visitor's attitudes; they are restorative parks and forest parks. The restorative park can provide restoration benefits for daily visitors, while forest parks can provide not only restoration effects but also visitor's hobby activities. Based on the duration of the visit to those parks, the level of visitor's sense of place in the forest park is higher than in the restorative park. The role of the architect and urban planner is needed to design urban parks that can develop visitor's sense of place, such as providing a place for attraction, physical activity, walking, photography, relaxation, and enjoy the atmosphere.
\end{abstract}

Keywords: Landscape architecture, time spent, sense of place, urban parks 


\section{Pendahuluan}

Seiring berkembangnya zaman, jumlah rasio area hijau di perkotaan semakin berkurang walaupun area hijau pada hakikatnya sangat dibutuhkan untuk kesehatan dan kesejahteraan masyarakat. Pembangunan kota menyebabkan kebutuhan masyarakat akan area parkir (Sang et al., 2016) dan fasilitas-fasilitas umum yang cenderung mengurangi area hijau untuk pengembangannya sehingga rasio pembangunan di dalam kota tidak seimbang. Dalam pembangunan infrastruktur kota, pemerintah kurang memperhatikan pengembangan dan penyediaan taman-taman di area kota (Fauziah et al., 2016) sehingga keberlanjutan area taman di tengah kota semakin terancam. Di sisi lain, taman memiliki peran penting bagi struktur kota, yaitu sebagai habitat berbagai macam burung (Gunawan \& Permana, 2018) dan sebagai ekosistem lingkungan alami (Sang et al., 2016). Bagi masyarakat kota, taman kota berfungsi sebagai penyedia sarana olahraga (Pietilä et al., 2015), sarana interaksi sosial (Porajouw et al., 2017), sarana kegiatan fisik (Roe et al., 2016), sarana rekreasi (Zhang et al., 2013) dan sarana restoratif (Sari et al., 2012) di kota. Secara tidak langsung, keberadaan taman-taman di tengah kota dapat meningkatkan taraf kesehatan (Sang et al., 2016) dan kesejahteraan pengunjung (Roe et al., 2016).

Taman kota adalah jenis area terbuka hijau yang paling diminati dan paling sering dikunjungi oleh masyarakat (Porajouw et al., 2017). Taman kota berlokasi di sekitar area perumahan sehingga masyarakat cenderung mengunjungi taman karena faktor aksesibilitas yang tinggi (Bahrini et al., 2017; Porajouw et al., 2017; Schipperijn et al., 2010; Wendel et al., 2012). Selain itu, beberapa pengunjung mengunjungi taman kota karena karakteristik visual taman (Fauziah et al., 2016) yang menarik dan atraktif. Mereka menyukai ragam kompleksitas pepohonan di taman (Harris et al., 2017) yang dapat memberikan kesan positif bahkan pada saat pertama kali berkunjung (Deng et al., 2017). Beberapa pengunjung taman datang karena desain lanskap dan sarana rekreasi yang diwadahinya (Jim \& Chen, 2006; Zhang et al., 2013). Selain itu, ada pula pengunjung yang pergi ke taman karena kualitas fisik taman yang sejuk dan asri (Sari et al., 2012).

Pengunjung menghabiskan waktu di taman dalam durasi kunjungan yang berbeda-beda. Pengunjung akan berlama-lama di taman jika mereka merasakan kenyamanan termal di taman tersebut (Binarti et al., 2008). Pengunjung taman rekreasi dapat menghabiskan waktu selama 4 sampai 5 jam, pengunjung taman safari sekitar 4 jam, dan pengunjung kebun raya sekitar 3 jam (Ingkadijaya et al., 2016). Mereka dapat berlama-lama di taman karena adanya atraksi yang dapat mereka nikmati. Sementara itu, anak-anak (6 sampai 17 tahun) dapat menghabiskan waktu sekitar 2 jam atau lebih di ruang terbuka publik (Prakoso \& Dewi, 2017). Perbedaan durasi ini mungkin disebabkan oleh jenis taman, usia, rekan (Ingkadijaya et al., 2016), dan kegiatan di taman. Kegiatan akan membentuk persepsi dan makna positif pengunjung di taman tersebut. Persepsi dan makna positif ini akan mendorong mereka untuk mengunjungi taman berkali-kali dalam durasi waktu yang lama. Sikap yang ditunjukkan oleh pengunjung ini dapat membangun sikap terhadap tempat atau sense of place pada taman tersebut.

Sikap terhadap tempat adalah sebuah sikap yang ditunjukkan pengunjung jika mereka memiliki pengalaman dan keterlibatan di suatu tempat (Shamai, 1991). Sikap ini dapat dibentuk berdasarkan kegiatan pengunjung, karakteristik tempat, dan makna tempat (Najafi \& Shariff, 2011). Selain itu, jenis skala (tipe) taman juga dapat mempengaruhi sikap ini sehingga pengunjung ingin berlama-lama menghabiskan waktu di taman (Shamai, 1991). Sikap terhadap tempat memiliki beberapa tingkatan, semakin tinggi tingkatannya maka semakin besar keinginan pengunjung untuk berpartisipasi menjaga taman. Berdasarkan Gussow dalam Relph (Relph, 1976), sikap terhadap tempat dibagi menjadi tiga tingkat, yaitu familiarity with place, an ordinary familiarity with place, 
dan profound familiarity with place. Shamai (1991) membagi tahapan tersebut menjadi tujuh tingkat, yaitu not having any sense of place, being located in a place, belonging to a place, attachment to a place, identifying with local goals, involvement in a place, dan sacrifice for a place. Tingkat place attachment pengunjung dapat ditingkatkan melalui durasi kunjungan (Smaldone, 2006) dan frekuensi kunjungan (Fauziah et al., 2016). Sikap terhadap tempat ini sangat penting dikaji agar pengunjung memiliki kepedulian tinggi dan partisipasi aktif terhadap taman melalui sikap pro-environmental behavior sehingga keberlanjutan taman tetap terjaga.

Penelitian ini dilakukan untuk mengetahui bagaimana pengelompokan jenis taman di area kota berdasarkan sikap pengunjung terhadap tempat. Sikap terhadap tempat yang dikaji adalah dari empat komponen, yaitu kegiatan pengunjung, karakteristik tempat, durasi kunjungan, dan jenis taman favorit pengunjung. Penelitian ini dapat memberikan kontribusi kepada arsitek lanskap atau perancang kota untuk merancang taman-taman kota yang dapat meningkatkan sikap terhadap tempat pengunjung sehingga kelestarian taman-taman kota akan terjaga.

\section{Bahan dan Metode}

Penelitian ini menggunakan metode kualitatif dengan pendekatan grounded theory yang bersifat eksploratif. Pada pendekatan grounded theory, peneliti tidak menggunakan pra-konsepsi atau hipotesis pada awal penelitian. Peneliti berusaha menggali faktor-faktor yang menyusun fenomena melalui data-data responden.

\subsection{Metode Pengumpulan Data}

Pengumpulan data dilakukan dengan menyebarkan kuesioner daring dengan metode non-random sampling dengan teknik snowball. Kuesioner daring berisi 11 pertanyaan, dengan 6 pertanyaan tentang demografi responden dan masing-masing 1 pertanyaan tentang taman favorit, alasan kunjungan, frekuensi kunjungan, kegiatan di taman, durasi kunjungan, dan partner kunjungan ke taman. Kuesioner disebarkan ke seseorang dan disebarkan lagi ke orang lain (Kumar, 2005). Jumlah data yang berhasil dikumpulkan selama 1 minggu di bulan September adalah 242 responden. Pengurangan data dilakukan pada 31 responden sehingga data yang diolah berasal dari 211 responden. Pengurangan ini ditujukan agar jawaban tersebut tidak mengintervasi data yang lain.

Responden penelitian adalah semua orang yang pernah mengunjungi taman minimal sekali. Jenis kelamin responden sebagian besar adalah perempuan (63\%), sementara sisanya adalah laki-laki (33\%). Responden harus memiliki latar belakang pendidikan minimal SMP (20 orang) agar data yang dikumpulkan lebih valid. Sebagian besar responden memiliki latar pendidikan S1 (108 orang), SMA (72 orang) dan hanya beberapa dari S2 (8 orang) dan S3 (3 orang). Responden berasal dari berbagai kota dan provinsi di Indonesia, seperti Bandung, Malang, NTB, Bali, Jabodetabek, dan sebagainya. Selain itu, sebagian besar responden berasal dari kalangan remaja (155 orang) dan responden lainnya adalah dewasa (32 orang) dan lansia (24 orang). Responden penelitian sebagian besar dari kalangan pelajar (110 orang) dan pekerja (88 orang), namun beberapa di antaranya tidak bekerja (12 orang) dan bahkan pensiun (1 orang).

\subsection{Metode Analisis Data}

Analisis data menggunakan analisis isi yang dilakukan melalui tiga tahap, yaitu analisis open coding, axial coding, dan selective coding (Creswell, 2007). Analisis open coding adalah analisis yang dilakukan dengan mengambil kata kunci dari jawaban openended responden dan mengelompokkannya ke dalam beberapa kategori. Hasil akhir dari 
analisis ini berupa distribusi frekuensi. Sementara itu, analisis axial coding dilakukan dengan melihat hubungan antar kategori melalui analisis korespondensi. Hasil dari analisis ini berupa dendrogram cluster hubungan antar kategori. Analisis terakhir, yaitu selective coding, dilakukan dengan membuat hipotesis akhir dari hubungan antar kategori-kategori tersebut. Hasil hipotesis merupakan hasil akhir dari penelitian ini yang berupa diagram hipotesis yang berisi tipologi taman.

\section{Hasil dan Diskusi}

Tahap awal penelitian adalah mengumpulkan kata kunci dari jawaban responden. Kata kunci tersebut kemudian dikelompokkan lagi menjadi beberapa kelompok kategori untuk merumuskan faktor-faktor karakteristik taman (Tabel 1). Satu jawaban responden dapat berisi sekitar tiga sampai lima variasi kata kunci karakteristik taman.

Tabel 1. Pemberian Kata Kunci dari Jawaban Alasan Kunjungan Responden

\begin{tabular}{|c|c|c|c|}
\hline No & Jawaban Responden & Kata Kunci & Kategori \\
\hline 169 & $\begin{array}{l}\text { "Di taman tersebut banyak pohon }{ }^{1} \text {, lebih asri }{ }^{2}, \text { luas }^{3} \text {, ada } \\
\text { kolam }{ }^{4} \text {, di sana juga ada banyak permainan } \text { buatan }^{\text {balah satunya flying fox" }}\end{array}$ & $\begin{array}{l}\text { 1.Pohon rindang } \\
\text { 2.Lanskap taman } \\
\text { 3.Luas } \\
\text { 4.Aspek air } \\
\text { 5.Sarana lengkap }\end{array}$ & $\begin{array}{l}\text { 1. Kenyamanan termal } \\
\text { 2.Desain lanskap } \\
\text { 3.Desain lanskap } \\
\text { 4.Desain lanskap } \\
\text { 5.Fasilitas }\end{array}$ \\
\hline 171 & $\begin{array}{l}\text { "Karena saya dapat melihat tanaman bunga }{ }^{1} \text { dan juga di } \\
\text { sana mempunyai spot untuk selfie }{ }^{2} \text {. Di sana juga ada } \\
\text { taman bermain yang sangat seru }{ }^{3} \text { " }\end{array}$ & $\begin{array}{l}\text { 1.Bunga } \\
\text { 2.Spot foto } \\
\text { 3.Sarana lengkap }\end{array}$ & $\begin{array}{l}\text { 1. Atraksi } \\
\text { 2. Desain lanskap } \\
\text { 3. Fasilitas }\end{array}$ \\
\hline
\end{tabular}

Berdasarkan pemberian kata kunci tersebut, terdapat 44 variasi kata kunci jawaban responden pada karakteristik taman. Variasi-variasi kata kunci tersebut dikelompokkan kembali menjadi 7 kelompok kategori, yaitu kenyamanan visual, kenyamanan termal, suasana, atraksi, desain taman, fasilitas, dan aksesibilitas (Tabel 2). Berdasarkan distribusi frekuensi, sebagian besar pengunjung pergi ke taman karena tertarik dengan fasilitas yang disediakan di taman, sementara ada pengunjung yang menyukai atraksinya.

Tabel 2. Pengelompokan Kata Kunci Karakteristik Taman

\begin{tabular}{|c|c|c|c|c|}
\hline No & Kata kunci & $\mathrm{F}$ & Kategori & $\mathrm{F}$ \\
\hline 1 & Akses mudah & 16 & Aksesibilitas & 31 \\
\hline 2 & Dekat masjid & 7 & & \\
\hline 3 & Dekat bangunan bersejarah & 1 & & \\
\hline 4 & Murah & 2 & & \\
\hline 5 & Ada akses parkir & 2 & & \\
\hline 6 & Dekat pusat perbelanjaan & 1 & & \\
\hline 7 & Dekat pasar & 1 & & \\
\hline 8 & Dekat rumah Nenek & 1 & & \\
\hline 9 & Dekat kampus & 1 & & \\
\hline 10 & Jenis hewan & 5 & Atraksi & 29 \\
\hline 11 & Atraksi & 13 & & \\
\hline 12 & Menarik & 7 & & \\
\hline 13 & Jenis tanaman & 5 & & \\
\hline 14 & Aspek air & 9 & Desain taman & 77 \\
\hline 15 & Lanskap taman & 54 & & \\
\hline 16 & Bunga & 8 & & \\
\hline 17 & Spot foto & 6 & & \\
\hline 18 & Luas & 11 & & \\
\hline 19 & Kuliner & 39 & Fasilitas & 104 \\
\hline 20 & Sarana lengkap & 51 & & \\
\hline 21 & Rekreasi & 2 & & \\
\hline 22 & Olahraga & 11 & & \\
\hline
\end{tabular}




\begin{tabular}{|c|c|c|c|c|}
\hline No & Kata kunci & $\mathrm{F}$ & Kategori & $\mathrm{F}$ \\
\hline 23 & Tempat kumpul & 10 & & \\
\hline 24 & Adanya bangunan penunjang & 2 & & \\
\hline 25 & Sarana penunjang & 2 & & \\
\hline 26 & Tempat membaca buku & 4 & & \\
\hline 27 & Tempat nongkrong & 2 & & \\
\hline 28 & Tempat historik & 1 & & \\
\hline 29 & Tempat belajar & 1 & & \\
\hline 30 & Fasilitas internet & 1 & & \\
\hline 31 & Tenang & 18 & Suasana & 64 \\
\hline 32 & Suasana nyaman & 37 & & \\
\hline 33 & Ramai & 12 & & \\
\hline 34 & Membangkitkan memori & 3 & & \\
\hline 35 & Restoratif & 3 & & \\
\hline 36 & Keamanan & 2 & & \\
\hline 37 & Pohon rindang & 54 & Kenyamanan termal & 90 \\
\hline 38 & Suhu udara nyaman & 23 & & \\
\hline 39 & Udara segar & 25 & & \\
\hline 40 & Polusi di taman sedikit & 3 & & \\
\hline 41 & Rapi & 14 & Kenyamanan visual & 34 \\
\hline 42 & Bersih & 27 & & \\
\hline 43 & Terawat & 2 & & \\
\hline 44 & Pencahayaan taman & 3 & & \\
\hline
\end{tabular}

Selanjutnya, analisis open coding juga dilakukan pada jawaban open-ended kegiatan yang dilakukan responden di taman (Tabel 3). Kegiatan responden memiliki variasi jawaban yang lebih beragam, sehingga kelompok kategori kegiatan lebih banyak. Satu jawaban responden berisi sekitar tiga atau lima variasi kegiatan di taman.

\section{Tabel 3. Pemberian Kata Kunci dari Jawaban Kegiatan Pengunjung}

\begin{tabular}{|c|c|c|c|}
\hline No & Jawaban Responden & Kata Kunci & Kategori \\
\hline 9 & $\begin{array}{l}\text { "Mengelilingi taman } \\
\underline{\text { duduk }} \text { " bermain }\end{array}$ & $\begin{array}{l}\text { 1. Berjalan kaki } \\
\text { 2. Bermain-main } \\
\text { 3. Duduk-duduk }\end{array}$ & $\begin{array}{l}\text { 1. Berjalan kaki } \\
\text { 2. Menikmati hiburan } \\
\text { 3. Duduk santai }\end{array}$ \\
\hline 176 & $\begin{array}{l}\text { "Latihan bernafas panjang1, } \\
\text { berbagai aktivitas manusia } 2 \text {, foto-foto }{ }^{3} "\end{array}$ & $\begin{array}{l}\text { 1. Menghirup udara segar } \\
\text { 2. Memperhatikan sekitar } \\
\text { 3. Fotografi }\end{array}$ & $\begin{array}{l}\text { 1. Memperhatikan suasana } \\
\text { 2. Memperhatikan suasana } \\
\text { 3. Fotografi }\end{array}$ \\
\hline
\end{tabular}

Berdasarkan pengambilan kata kunci, terdapat 31 variasi kata kunci yang kemudian dikelompokkan menjadi 13 kategori kegiatan. Kategori kegiatan tersbebut meliputi interaksi sosial, duduk santai, melihat atraksi, mengerjakan tugas, makan makanan, tujuan khusus, bersepeda dan berkuda, berjalan kaki, menikmati suasana, relaksasi, bermain gawai, fotografi, serta berolahraga (Tabel 4). Berdasarkan distribusi frekuensi, sebagian besar pengunjung taman lebih sering duduk santai dibandingkan bersepeda dan berkuda.

Tabel 4. Pengelompokan Kata Kunci Jenis Kegiatan di Taman

\begin{tabular}{cllll}
\hline No & Kata kunci & F & Kategori & F \\
\hline 1 & Duduk-duduk & 53 & Duduk santai & 65 \\
2 & Nongkrong & 12 & & 44 \\
\hline 3 & Fotografi & 44 & Fotografi & 8 \\
\hline 4 & Bermain HP & 5 & Bermain gawai & \\
5 & Mendengarkan musik & 2 & Menikmati hiburan & 40 \\
\hline 6 & Melihat pertunjukan & 4 & & 6 \\
7 & Bermain-main & 31 & Bersepeda \& berkuda & \\
8 & Menaiki wahana & 5 & & 58 \\
\hline 9 & Bersepeda & 1 & Makan makanan & \\
10 & Berkuda & 58 & & \\
\hline 11 & Kuliner & & & \\
\hline
\end{tabular}




\begin{tabular}{|c|c|c|c|c|}
\hline No & Kata kunci & $\mathrm{F}$ & Kategori & $\mathrm{F}$ \\
\hline 12 & Membaca buku & 14 & Mengerjakan tugas & 17 \\
\hline 13 & Mengerjakan tugas & 3 & & \\
\hline 14 & Berolahraga & 31 & Berolahraga & 51 \\
\hline 15 & Lari & 25 & & \\
\hline 16 & Interaksi sosial & 50 & Interaksi sosial & 55 \\
\hline 17 & Berkumpul & 4 & & \\
\hline 18 & Berpartisipasi dalam acara & 7 & & \\
\hline 19 & Rekreasi & 6 & Relaksasi & 30 \\
\hline 20 & Santai & 14 & & \\
\hline 21 & Istirahat & 4 & & \\
\hline 22 & Tidur-tiduran & 3 & & \\
\hline 23 & Refreshing & 3 & & \\
\hline 24 & Jalan-jalan & 36 & Berjalan & 36 \\
\hline 25 & Menikmati suasana & 13 & Menikmati suasana & 34 \\
\hline 26 & Menikmati pemandangan & 18 & & \\
\hline 27 & Menghirup udara segar & 4 & & \\
\hline 28 & Memperhatikan sekitar & 6 & & \\
\hline 29 & Menemani anak & 4 & Tujuan khusus & 9 \\
\hline 30 & Berjualan & 1 & & \\
\hline 31 & Membawa peliharaan & 1 & & \\
\hline
\end{tabular}

\subsection{Hubungan antara Jenis Taman dan Durasi Kunjungan Taman}

Hubungan antara jenis taman dan durasi kunjungan dilakukan melalui analisis korespondensi. Taman favorit telah dibagi menjadi tiga jenis yaitu taman kota, taman tematik, dan hutan kota. Sementara durasi kunjungan dibagi menjadi empat yaitu kurang dari 1 jam, 1-2 jam, 2-3 jam, dan lebih dari 3 jam. Berdasarkan hasil analisis, keduanya memiliki hubungan yang signifikan dengan P-Value 0.0027 dan Likelihood Ratio 0.0057. Kelompok taman-taman kota dapat dibagi menjadi 3 kelompok besar. Kelompok hutan kota yang cenderung membuat pengunjung merasa betah selama lebih dari 3 jam; kelompok taman kota dalam durasi 1-2 jam; serta kelompok taman tematik dalam durasi kurang dari 1 jam bahkan selama 2-3 jam (Gambar 1).

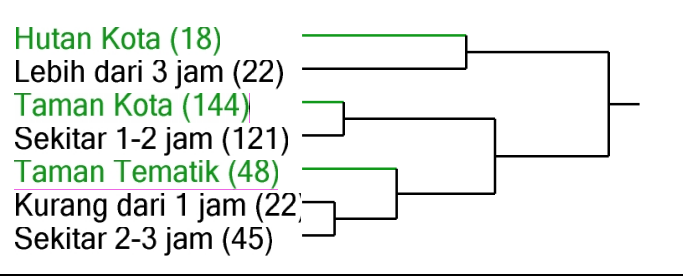

Gambar 1. Diagram Cluster Hubungan Jenis Taman dan Durasi Kunjungan

Kelompok hutan kota adalah jenis taman kota yang dikunjungi dalam durasi terlama (Gambar 1). Hutan kota meliputi Kebun Binatang Ragunan, Taman Kaliurang Yogyakarta, Taman Hutan Kota Malabar Malang, dan sebagainya. Jenis taman safari dan kebun binatang termasuk dalam kelompok hutan kota dan dapat membuat pengunjung menghabiskan waktu selama 3-4 jam (Ingkadijaya et al., 2016). Sementara itu, taman kota cenderung dikunjungi dalam 1-2 jam saja. Kelompok taman kota adalah taman AlunAlun Kota di beberapa kota Indonesia. Taman tematik cenderung dikunjungi dalam durasi waktu paling singkat (kurang dari 1 jam) dan lumayan lama (antara 2-3 jam). Kelompok taman tematik adalah Taman Lalu Lintas, Taman Selecta Batu, Taman Flora Surabaya, dan sebagainya yang hanya dikembangkan di kota tertentu.

Durasi kunjungan menentukan seberapa besar keinginan pengunjung untuk berlama-lama di dalam taman. Semakin lama durasi kunjungan di taman, maka semakin besar pula keterlibatan pengunjung di dalam taman. Akan tetapi, durasi kunjungan tidak dapat menunjukkan besarnya tingkat emosional pengunjung terhadap taman. 
Analisis korespondensi menunjukkan adanya hubungan yang signifikan antara jenis taman dengan jenis kegiatan pengunjung di taman dengan P-Value 0.0079 dan Likelihood Ratio 0.0051. Berdasarkan hasil analisis, jenis taman dan kegiatan dapat dibagi menjadi 2 kelompok besar (Gambar 2), yaitu kegiatan di hutan kota dan kegiatan di taman kota dan tematik. Pengunjung di hutan kota cenderung melakukan kegiatan berjalan kaki, menikmati suasana, relaksasi, bermain gawai, fotografi, dan berolahraga. Sementara itu, pengunjung di taman kota dan taman tematik cenderung melakukan aktivitas yang sama, yaitu interaksi sosial, duduk santai, melihat hiburan, mengerjakan tugas, makan makanan, tujuan khusus, dan bersepeda dan berkuda.

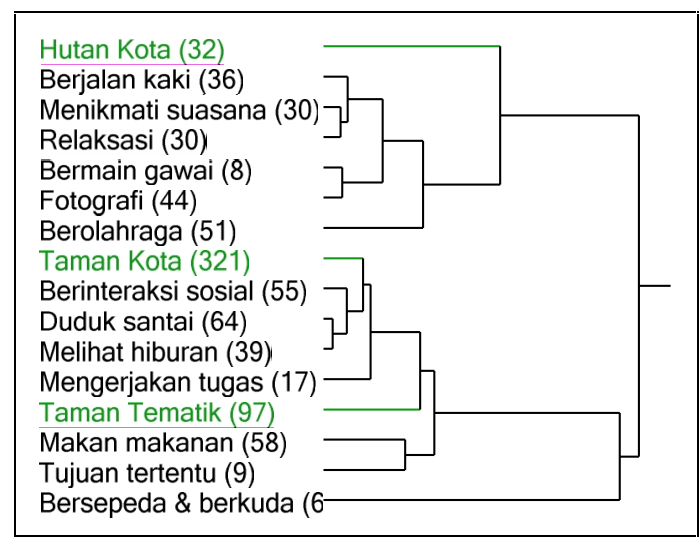

Gambar 2. Diagram Cluster Hubungan Jenis Taman dan Kegiatan di Taman

Sebagian besar pengunjung hutan kota melakukan kegiatan rekreasi aktif (Gambar 2). Pengunjung hutan kota adalah mereka yang memiliki hobi tertentu seperti berolahraga, berjalan kaki, dan fotografi. Hal ini kemungkinan besar disebabkan oleh ketersediaan fasilitas jogging track (Armas \& Soelaiman, 2017) di hutan kota sehingga pengunjung merasa lebih leluasa untuk melakukan kedua kegiatan tersebut. Beberapa pengunjung juga menikmati suasana, relaksasi, ataupun bermain gawai.

Sementara itu, pengunjung taman kota dan taman tematik cenderung melakukan kegiatan rekreasi pasif (Gambar 2). Sebagian besar pengunjung berkumpul dan interaksi sosial (Whiting et al., 2017), duduk santai, menikmati kuliner, dan melakukan kegiatan restoratif (Sari et al., 2012) di taman kota. Taman tersebut menyediakan berbagai fasilitas utama yang dapat mewadahi kegiatan yang ingin mereka lakukan. Beberapa diantaranya melakukan kegiatan khusus, yaitu kegiatan yang dilakukan dengan maksud tertentu seperti penggalangan dana, berjualan, menemani anak bermain, dan sebagainya. Beberapa taman kota menyediakan fasilitas kuda yang dapat dikendarai pengunjung.

Seluruh kegiatan yang cenderung dilakukan oleh pengunjung harus diwadahi di taman-taman kota. Kegiatan-kegiatan tersebut memiliki peran penting dalam membentuk sikap mereka terhadap tempat (Najafi \& Shariff, 2011). Kegiatan dapat menentukan seberapa besar keterlibatan pengunjung di dalam taman dan durasi kunjungan di taman tersebut. Dengan adanya fasilitas taman yang memadai, berbagai kegiatan yang dapat dilakukan pengunjung di taman akan terwadahi.

\subsection{Hubungan antara Karakteristik Taman dan Durasi Kunjungan}

Analisis korespondensi menunjukkan adanya hubungan yang cenderung signifikan antara karakteristik taman dan durasi kunjungan dengan P-value 0.0721 dan Likelihood Ratio 0.0281. Berdasarkan hasil analisis, terdapat tiga kelompok taman favorit, 
yaitu taman yang dikunjungi dalam waktu kurang dari 1 jam karena suasana taman; taman yang dikunjungi 1-3 jam karena fasilitas taman, desian taman, kenyamanan termal, kenyamanan visual, dan kemudahan akses menuju taman; dan taman yang dikunjungi lebih dari 3 jam karena atraksi yang diberikan oleh taman (Gambar 3).

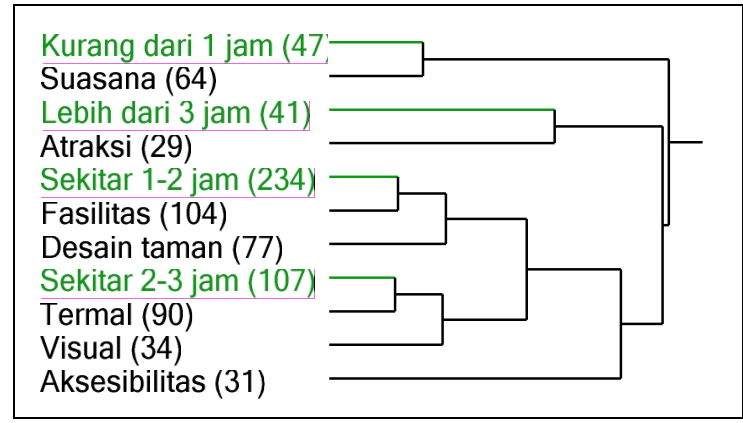

Gambar 3. Diagram Cluster Karakteristik Tamn dan Durasi Kunjungan

Karakteristik taman menentukan durasi kunjungan pengunjung ke taman favorit. Karakteristik taman berbeda-beda sesuai dengan jenis dan branding yang ingin ditunjukkan oleh taman tersebut (Fauziah et al., 2016). Taman yang dikunjungi oleh pengunjung dalam durasi lama (lebih dari 3 jam) cenderung memiliki atraksi yang menarik. Atraksi dapat membuat pengunjung merasa betah di taman. Taman yang dapat memunculkan suasana yang berbeda dengan tempat-tempat lain cenderung dikunjungi pengunjung dalam durasi yang singkat (kurang dari 1 jam). Sementara itu, taman yang memiliki fasilitas lengkap, aksesibilitas mudah, desain menarik, serta memiliki kualitas visual dan termal yang baik cenderung dikunjungi oleh pengunjung dalam durasi sedang (antara 1-3 jam). Perbedaan karakteristik taman ternyata dapat membagi jenis tamantaman kota berdasarkan durasi kunjungan pengunjung selama berada di taman-taman tersebut. Pengunjung cenderung merasa ingin berlama-lama di dalam taman jika mereka merasa nyaman (Rachman \& Kusuma, 2014).

\subsection{Hipotesis Tipologi Taman-Taman Kota berdasarkan Sikap Pengunjung}

Sikap yang ditunjukkan pengunjung terhadap taman-taman di kota berbeda-beda. Berdasarkan hasil analisis, taman-taman kota dapat dikategorikan menjadi dua tipologi besar, yaitu tipologi taman restorasi dan taman hutan (Gambar 4). Tipologi taman restorasi adalah taman-taman di kota (taman kota dan taman tematik) yang dapat dijangkau dan dimanfaatkan oleh pengunjung sehari-hari. Taman restorasi cenderung berada di sekitar rumah pengunjung (Gidlof-Gunnarsson \& Ohrstrom, 2007). Sementara itu, taman hutan adalah hutan kota yang memiliki berbagai atraksi menarik. Taman hutan cenderung mewadahi pengunjung yang memiliki hobi tertentu. Tidak semua kota di Indonesia memiliki taman hutan karena ukurannya lebih luas dengan pepohonan yang lebih rindang dan lebat dibandingkan dengan taman restorasi.

Durasi kunjungan yang dihabiskan oleh pengunjung di kedua tipologi taman tersebut berbeda-beda (Gambar 4). Pengunjung cenderung menghabiskan waktu antara kurang dari 1 jam hingga 3 jam di taman restorasi dan lebih dari 3 jam di taman hutan. Hal ini mungkin disebabkan oleh atraksi alami, seperti ragam (Deng et al., 2017) dan kompeksitas (Harris et al., 2017) jenis tanaman. Selain itu, pengunjung cenderung memanfaatkan atraksi buatan yang diwadahinya seperti wahana untuk bermain.

Pengunjung cenderung meghabiskan waktu di taman restorasi dalam waktu yang relatif singkat hingga lama. Penelitian terdahulu menyatakan bahwa pengunjung yang cenderung memanfaatkan taman sekitar adalah pada umumnya wanita, orang tua, dan 
berpenghasilan rendah (Sang et al., 2016) sehingga perbedaan durasi kunjungan mungkin disebabkan oleh kepentingan pengunjung yang berbeda-beda. Taman restorasi memiliki aksesibilitas yang mudah karena berada dekat dengan rumah penduduk (GidlofGunnarsson \& Ohrstrom, 2007) dan fasilitas umum lainnya seperti toko, tempat kerja, dan bangunan komersil (Thwaites et al., 2005) sehingga aksesibilitas menuju taman lebih mudah. Aksesibilitas adalah salah satu faktor terpenting yang mendorong pengunjung melakukan kegiatan di taman kota (Adhitama, 2013). Taman restorasi menyediakan suasana yang menenangkan yang dapat memulihkan pengalaman stres pengunjung (Korpela et al., 2010), akan tetapi efek restoratif yang diberikan taman berbeda-beda sesuai dengan jenis tamannya (Gatersleben \& Andrews, 2013). Desain taman adalah salah satu faktor karakteristik taman yang dapat menentukan preferensi kunjungan (Jim \& Chen, 2006). Kualitas visual (Fauziah et al., 2016) yang menarik dan kualitas termal yang nyaman (Binarti et al., 2008) juga dapat membuat pengunjung merasa betah. Kualitas visual dapat diperoleh melalui perawatan taman restorasi (kebersihan, kerapian, dan sebagainya) dan kualitas termal melalui penataan lansekap taman (pohon yang rindang, udara yang segar, dan sebagainya). Kedua faktor ini sangat diperlukan untuk mendukung terjadinya restorasi sehingga pengunjung taman akan merasa segar kembali setelah dari taman.

Durasi kunjungan di kedua tipologi taman tersebut menunjukkan ragam jenis kegiatan yang dilakukan pengunjung (Gambar 4). Jenis kegiatan di taman restorasi cenderung kegiatan pasif dan di taman hutan cenderung kegiatan aktif. Kegiatan aktif tersebut merupakan kegiatan hobi (seperti berolahraga, jalan kaki, dan fotografi) dan beberapa kegiatan restorasi (seperti menikmati suasana dan relaksasi). Hal ini menunjukkan bahwa taman hutan juga dapat menjadi taman restorasi dalam kondisi tertentu. Taman hutan yang memiliki tingkat keterbukaan, tidak memiliki area persembunyian (Gatersleben \& Andrews, 2013), dan tidak gelap (Milligan \& Bingley, 2007) dianggap memiliki efek restorasi. Pengunjung yang ingin berjalan-jalan ke taman hutan adalah pengunjung dengan tingkat stress tinggi (Linda et al., 2013).

Taman restorasi cenderung mewadahi kegiatan pasif yang biasa dilakukan pengunjung. Hal ini disebabkan oleh keinginan pengunjung untuk melakukan kegiatan yang berbeda dengan kegiatan sehari-hari. Pengunjung taman ini mungkin adalah pengunjung yang cenderung memiliki rutinitas pekerjaan atau kegiatan sibuk lainnya. Adapun aktivitas yang dilakukan adalah kegiatan duduk, kegiatan kuliner, interaksi sosial, menikmati hiburan di taman, mengerjakan tugas dan membaca buku, serta mengendarai sepeda dan kuda. Taman restorasi sering dimanfaatkan untuk kegiatan sosial (Porajouw et al., 2017) karena taman adalah salah satu wadah yang dapat mengumpulkan masyarakat multi-kultur di satu tempat (Roe et al., 2016). Kuliner di taman sangat beragam dan terletak di sepanjang jalan. Semua jenis kegiatan pasif tersebut cenderung dilakukan pengunjung di taman restorasi.

Kedua tipologi taman tersebut adalah representasi tipologi dari taman-taman kota di beberapa daerah di Indonesia. Apabila dilihat dari pola diagram (Gambar 4), pengunjung di taman hutan memiliki sikap terhadap tempat yang lebih tinggi dibandingkan dengan pengunjung taman restorasi. Hal ini disebabkan oleh perbedaan durasi kunjungan yang dihabiskan oleh pengunjung di kedua tipologi taman. Durasi kunjungan menentukan seberapa besar seseorang menerima makna dari tempat tersebut. Selain itu, penelitian sebelumnya menyebutkan bahwa tingkatan sikap terhadap tempat tergantung pada skala (tipe) taman walaupun pengukurannya hanya bergantung pada makna tempat (Shamai, 1991). Taman hutan memiliki skala yang lebih besar dibandingkan taman restorasi sehingga kemungkinan besar tingkat sikap terhadap tempatnya berbeda. Sikap terhadap tempat adalah hal yang kompleks karena melibatkan kekuatan ikatan emosional pengunjung dengan tempat tersebut (Shamai, 1991). 
Penelitian ini belum dapat mengungkapkan bagaimana makna tempat bagi pengunjung sehingga tingkat sikap terhadap tempat secara keseluruhan belum bisa dinilai.

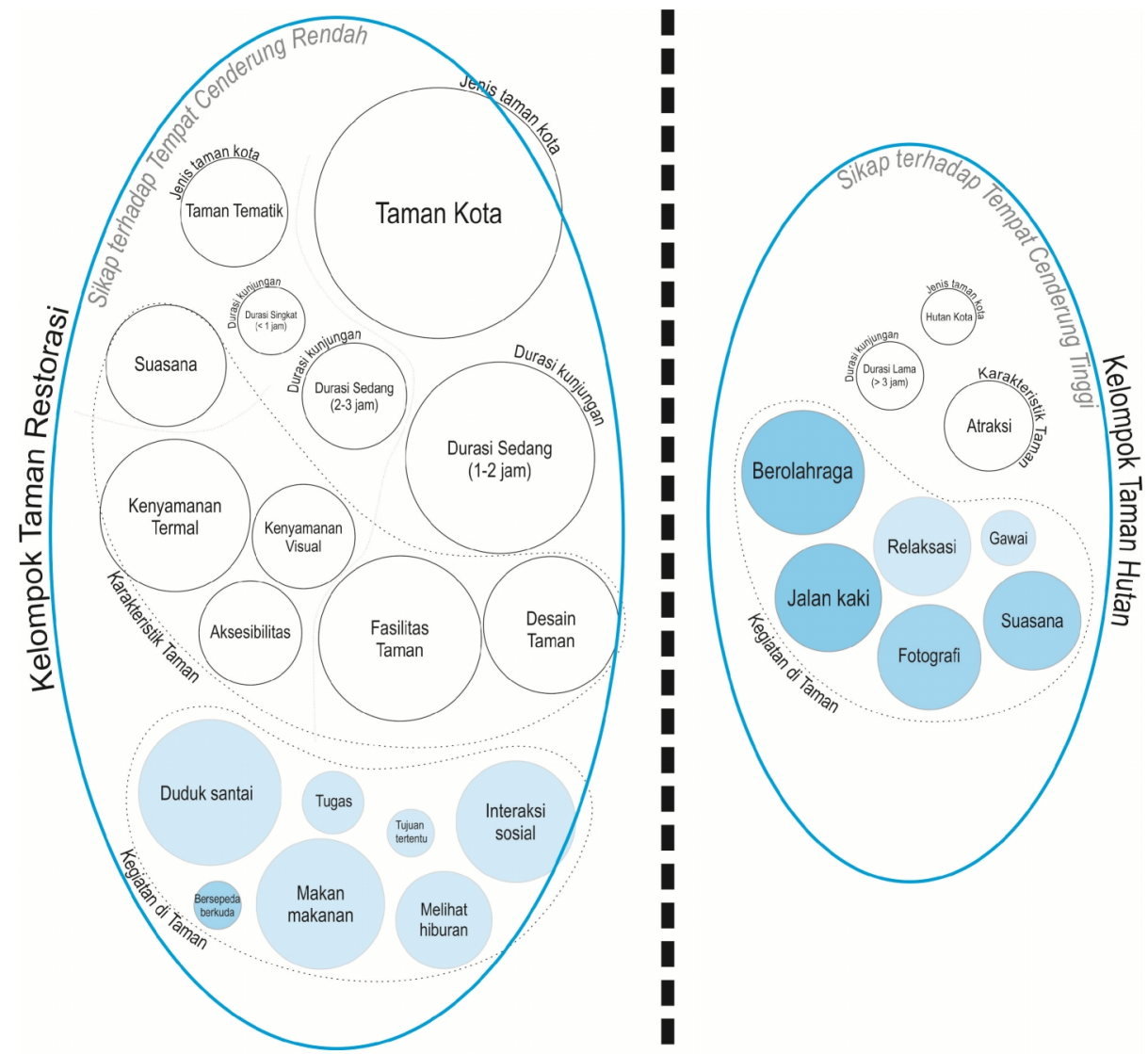

Gambar 4. Diagram Cluster Karakteristik Taman dan Durasi Kunjungan

Tingkat sikap pengunjung terhadap tempat di taman-taman kota harus ditingkatkan agar kelestarian taman tetap terjaga. Taman kota bukanlah tempat yang dapat membentuk kepribadian pengunjung untuk pro-environmental behaviour karena tidak akan ada sanksi atau halangan (Halpenny, 2010) sehingga hanya beberapa pengunjung saja yang memiliki sikap tersebut. Pada tingkat attachment to the place, beberapa pengunjung masih menunjukkan sikap pro-environmental behaviour yang rendah (Halpenny, 2010) sementara pengunjung lainnya menunjukkan sikap yang tinggi tergantung pada beberapa komponen penyusun place attachment (Buta et al., 2014). Untuk menjaga kelestarian pemanfaatan taman-taman kota, pengunjung harus berada pada tingkat attachment to the place atau bahkan lebih tinggi di dalam level sense of place. Peran arsitek dan perancang kota sangat diharapkan untuk mendesain taman kota yang dapat meningkatkan sikap pengunjung terhadap tempat.

\section{Simpulan}

Penelitian ini mengungkap bahwa durasi kunjungan membagi tipologi taman berdasarkan sikap pengunjung terhadap tempat. Taman restorasi dapat memberikan tingkat sikap terhadap tempat yang lebih rendah dibandingkan dengan taman hutan. Taman hutan cenderung membuat pengunjung ingin berlama-lama berada di dalamnya karena mereka dapat melakukan kegiatan hobi dan restorasi di hutan. Sementara itu, taman restorasi cenderung mewadahi kegiatan restorasi, intetraksi sosial, dan beragam 
kegiatan yang berbeda dengan kegiatan sehari-hari. Penelitian lanjutan tentang sikap ini akan sangat diperlukan di Indonesia karena jarang dilakukan sebelumnya.

Penelitian ini memiliki beberapa kekurangan dari segi pembahasan dan pengambilan data. Penelitian belum mengungkap ikatan emosional dan makna tempat, yang merupakan elemen pembentuk sikap terhadap tempat (Najafi \& Shariff, 2011). Penelitian terkait 3 komponen pembentuk tempat (place), yaitu makna tempat (place meaning), karakteristik tempat (setting), dan kegiatan (activitivity) yang dapat mengungkap fenomena sikap terhadap tempat (sense of place) secara utuh sangat perlu dilakukan. Selain itu, pengambilan data penelitian dilakukan dengan kuesioner daring yang mungkin memiliki hasil yang sedikit berbeda jika disebar secara langsung. Hasil penelitian ini juga belum memiliki tingkat reabilitas yang tinggi karena hanya dilakukan sekali dan harus ditelusuri lebih lanjut dengan penelitian replikasi.

\section{Ucapan terima kasih}

Penulis mengucapkan terima kasih kepada teman-teman kuliah AR 5142 Analisis Data yang telah ikut membagikan kuesioner ini kepada responden.

\section{Daftar Pustaka}

Adhitama, M. S. (2013). Faktor Penentu Setting Fisik dalam Beraktifitas di Ruang Terbuka Publik "Studi Kasus Alun-Alun Merdeka Kota Malang." Jurnal RUAS, 11(2), 1-9.

Armas, D. Q., \& Soelaiman, T. M. A. (2017). Kegiatan Joging dan Tempat-Tempat Aktivitas Joging di. In Temu Ilmiah IPLBI 2017 (pp. 47-52).

Bahrini, F., Bell, S., \& Mokhtarzadeh, S. (2017). The Relationship between The Distribution and Use Patterns of Parks and Their Spatial Accessibility at The City Level: A Case Study from Tehran, Iran. Urban Forestry \& Urban Greening, 27, 332-342. https://doi.org/10.1016/j.ufug.2017.05.018

Binarti, F., Kusuma, H. E., Wonorahardjo, S., \& Triyadi, S. (2008). Peranan Unsur-Unsur Ruang Terbuka pada Tingkat Kenyamanan Termal Outdoor: Antara Persepsi dan Pengetahuan. Jurnal Arsitektur KOMPOSISI, 12(1), 41-52.

Buta, N., Holland, S. M., \& Kaplanidou, K. (2014). Local Communities and Protected Areas : The Mediating Role of Place Attachment for Pro-environmental Civic Engagement. Journal of Outdoor Recreation and Tourism, 5-6, 1-10. https://doi.org/10.1016/j.jort.2014.01.001

Creswell, J. W. (2007). Qualitative Inquiry and Research Design: Choosing among Five Approaches (2nd ed.). London: SAGE Publications.

Deng, J., Andrada, R., \& Pierskalla, C. (2017). Visitors ' and Residents ' Perceptions of Urban Forests for Leisure in Washington D . C. Urban Forestry \& Urban Greening, 28, 1-11.

Fauziah, A., Santosa, I., \& Wahjudi, D. (2016). Thematic Concept on The Physical Element of Open Space Towards People's Place Attachment in The City of Bandung. Global Journal of Arts, Humanities and Social Sciences, 4(7), 48-65.

Gatersleben, B., \& Andrews, M. (2013). When Walking in Nature Is Not Restorative - The Role of Prospect and Refuge. Health \& Place, 20, 91-101. https://doi.org/10.1016/j.healthplace.2013.01.001

Gidlof-Gunnarsson, A., \& Ohrstrom, E. (2007). Noise and well-being in urban residential environments: The potential role of perceived availability to nearby green areas. Landscape and Urban Planning, 83(2-3), 115-126. https://doi.org/10.1016/j.landurbplan.2007.03.003

Gunawan, A., \& Permana, S. (2018). Konsep Desain Ekologis Ruang Terbuka Hijau di Sudirman Central Business District (SCBD) sebagai Habitat Burung. Tata Loka, 20(2), 181-194.

Halpenny, E. A. (2010). Pro-Environmental Behaviours and Park Visitors: The Effect of Place Attachment. Journal of Environmental Psychology, 30(4), 409-421. https://doi.org/10.1016/j.jenvp.2010.04.006

Harris, V., Kendal, D., Hahs, A. K., \& Threlfall, C. G. (2017). Green space context and vegetation complexity shape people' s preferences for urban public parks and residential gardens. 
Landscape Research, 6397(April). https://doi.org/10.1080/01426397.2017.1302571

Ingkadijaya, R., Damanik, J., Putra, H. S. A., \& Nopirin. (2016). Aktivitas Wisata Pilihan Keluarga Perkotaan. Jurnal Khasanah Ilmu, 7(1), 39-44.

Jim, C. Y., \& Chen, W. Y. (2006). Perception and Attitude of Residents Toward Urban Green Spaces in Guangzhou (China). PROFILE, 38(3), 338-349. https://doi.org/10.1007/s00267-0050166-6

Korpela, K. M., Ylen, M., Tyrvainen, L., \& Silvennoinen, H. (2010). Favorite Green, Waterside and Urban Environments, Restorative Experiences and Perceived Health in Finland. Health Promotion International, 25(2), 200-209. https://doi.org/10.1093/heapro/daq007

Linda, S., Van den Berg, A. E., \& De Groot, J. I. M. (2013). Environmental Psychology: An Introduction. West Sussex: The British Psychological Society and John Wiley \& Sons Ltd.

Milligan, C., \& Bingley, A. (2007). Restorative Places or Scary Spaces ? The Impact of Woodland on the Mental Well-being of Young Adults. Health \& Place, 13, 799-811. https://doi.org/10.1016/j.healthplace.2007.01.005

Najafi, M., \& Shariff, M. K. B. M. (2011). The Concept of Place and Sense of Place In Architectural Studies. International Journal of Human and Social Sciences, 6(3), 187-193.

Pietilä, M., Neuvonen, M., Borodulin, K., Korpela, K., \& Sievänen, T. (2015). Relationships between exposure to urban green spaces , physical activity and self-rated health. Journal of Outdoor Recreation and Tourism, 10, 44-54. https://doi.org/10.1016/j.jort.2015.06.006

Porajouw, E. F., Poluan, R. J., \& Mastutie, F. (2017). Efektivitas Ruang Terbuka Publik di Kota Tomohon. Spasial, 4(1), 136-148.

Prakoso, S., \& Dewi, J. (2017). Rasa Kelekatan Anak pada Ruang Publik Terpadu Ramah Anak (RPTRA). NALARs, 17(1), 1-10.

Rachman, R. A., \& Kusuma, H. E. (2014). Definisi Kebetahan dalam Ranah Arsitektur dan Lingkungan- Perilaku. In Temu Ilmiah IPLBI 2014 (pp. 55-60).

Relph, E. (1976). Place and Placelessness. London: Pion Limited.

Roe, J., Aspinall, P. A., \& Thompson, C. W. (2016). Understanding Relationships between Health , Ethnicity, Place and the Role of Urban Green Space in Deprived Urban Communities. International Journal of Environmental Research and Public Health, 13(681), 1-21. https://doi.org/10.3390/ijerph13070681

Sang, O., Knez, I., \& Gunnarsson, B. (2016). The Effects of Naturalness , Gender , and Age on How Urban Green Space is Perceived and Used. Urban Forestry \& Urban Greening, 18, 268-276. https://doi.org/10.1016/j.ufug.2016.06.008

Sari, A. A., Kusuma, H. E., \& Tedjo, B. (2012). Tempat Favorit Mahasiswa sebagai Sarana Restorative. In Ikatan Peneliti Lingkungan Binaan Indonesia (Vol. 1, pp. 5-18).

Schipperijn, J., Ekholm, O., Stigsdotter, U. K., Toftager, M., Bentsen, P., Kamper-jørgensen, F., \& Randrup, T. B. (2010). Factors influencing the use of green space : Results from a Danish national representative survey, 95, 130-137. https://doi.org/10.1016/j.landurbplan.2009.12.010

Shamai, S. (1991). Sense of Place : an Empirical Measurement. Geoforum, 22(3), 347-358.

Smaldone, D. (2006). The Role of Time in Place Attachment. In Proceedings of the 2006 Northeeastern Recreation Research Symposium (pp. 47-56).

Thwaites, K., Helleur, E., \& Simkins, I. M. (2005). Restorative Urban Open Space : Exploring the Spatial Configuration of Human Emotional Fulfilment in Urban Open Space Restorative Urban Open Space : Exploring the Spatial Configuration of Human Emotional Fulfilment in Urban Open Space. Landscape Research, 30(4), 525-547. https://doi.org/10.1080/01426390500273346

Whiting, J. W., Larson, L. R., Green, G. T., \& Kralowec, C. (2017). Outdoor Recreation Motivation and Site Preferences across Diverse Racial/Ethnic Groups : A Case Study of Georgia State Parks. Journal of Outdoor Recreation and Tourism, 18, 10-21. https://doi.org/10.1016/j.jort.2017.02.001

Zhang, H., Chen, B., Sun, Z., \& Bao, Z. (2013). Landscape Perception and Recreation Needs in Urban Green Space in Fuyang, Hangzhou, China. Urban Forestry \& Urban Greening, 12(1), 44-52. https://doi.org/10.1016/j.ufug.2012.11.001 